\title{
The Ethics of Climate Nudges: Central Issues for Applying Choice Architecture Interventions to Climate Policy
}

\author{
Helena SIIPI*(i) and Polaris $\mathrm{KOI}^{* *}$
}

While nudging has garnered plenty of interdisciplinary attention, the ethics of applying it to climate policy has been little discussed. However, not all ethical considerations surrounding nudging are straightforward to apply to climate nudges. In this article, we overview the state of the debate on the ethics of nudging and highlight themes that are either specific to or particularly important for climate nudges. These include: the justification of nudges that are not self-regarding; how to account for climate change denialists; transparency; knowing the right or best behaviours; justice concerns; and whether the efficacy of nudges is sufficient for nudges to be justified as a response to the climate crisis. We conclude that climate nudges raise distinct ethical questions that ought to be considered in developing climate nudges.

\section{INTRODUCTION}

Non-coercive interventions on choice architectures, commonly referred to as "nudges", aim to tweak the circumstances in which decisions are made in order to improve decision outcomes. While nudges remain controversial, they are also the subject of much enthusiasm as a "soft" means to steer citizens without having to resort to "hard" regulations. Nudges have been suggested or carried out in various fields of life including healthy eating, ${ }^{1}$ physical activity, ${ }^{2}$ retirement saving, ${ }^{3}$ organ donation ${ }^{4}$ and charitable giving. ${ }^{5}$

\footnotetext{
* Department of Philosophy, Contemporary History and Political Science, University of Turku, Finland; email: helsii@utu.fi. This contribution was written in the context of a research project that received funding from the Strategic Research Council at the Academy of Finland (grant number 335186).

** Department of Philosophy, Contemporary History and Political Science, University of Turku, Finland; email: polaris.koi@utu.fi.

1 R Cadario and P Chandon, "Which healthy eating nudges work best?" (2020) 39 Marketing Science 465.

2 Y Lin, M Osman and R Ashcroft, "Nudge: concept, effectiveness, and ethics" (2017) 39 Basic and Applied Social Psychology 293.

3 CR Sunstein and RR Thaler, "Libertarian paternalism is not an oxymoron" (2003) 70 The University of Chicago Law Review 1159.

4 B Engelen, "Ethical criteria for health-promoting nudges: a case-by-case analysis" (2019) 19 American Journal of Bioethics 48, 49.

5 J Hobbs, "Nudging charitable giving: the ethics of nudge in international poverty reduction" (2017) 10 Ethics \& Global Politics 37.
} re-use, distribution, and reproduction in any medium, provided the original work is properly cited. 
In this paper, the focus is on what we term "climate nudges". A climate nudge is any intentional modification of the choice architecture that aims to alter citizen behaviour towards climate-friendly actions while maintaining their earlier alternatives. For climate nudges, they both (1) encourage ways of behaviour that contribute to mitigating climate change and (2) are motivated by climate concerns. Requirement (1) limits climate nudges to ones that (according to the best available evidence) enhance behaviour that is good for the climate. Thus, a nudge to plant trees can be a climate nudge whereas a nudge to clear cut a forest is not one. Requirement (2) limits climate nudges to ones that are carried out in order to enhance the state of the climate. Thus, a nudge for bicycling to work, for example, is a climate nudge if it is carried out for climate reasons and fails to be one if it is done in order to benefit the health of the nudgees (even though it may factually contribute also to climate actions). Requirement (2) does not limit climate nudges to ones that are motivated solely by climate concerns. A climate nudge may well - in addition to climate concerns - also have other motivations behind it.

Even though nudges aimed at enhancing environmentally responsible behaviour have been designed, ${ }^{6,7,8}$ to date, ethical discussion concerning the use of nudges for climate change mitigation purposes has been sparse. ${ }^{9,10,11}$ In what follows, we spell out ethical topics that are to some extent specific to climate nudges. We consider an ethical factor specific to climate nudges when there is either an ethically relevant disanalogy between climate nudges and nudges in other contexts or when the ethical factor concerns most climate nudges and is less central in other contexts of nudging. We pool together ethical considerations that are specific to climate nudges as a starting point for further academic discussion of climate nudges and as a tool for their ethical assessment. However, this paper does not provide an exhaustive list that would cover all ethical issues relevant to climate nudges. There are many ethical issues that are relevant to all nudges that are not discussed in this paper. One example of such a question is whether nudges retain the freedom and autonomy of the nudgees. ${ }^{12,13,14}$ In addition, some ethical questions may arise only with respect to very few climate nudges and still be crucial for the ethical assessment of those particular nudges.

6 RH Thaler and CR Sunstein, Nudge: Improving Decisions about Health, Wealth, and Happiness (New Haven, CT, Yale University Press 2008) p 185.

7 JL Roberts, "Nudge-proof: distributive justice and the ethics of nudging" (2018) 116 Michigan Law Review 1045, 1063.

8 PG Hansen and AM Jespersen, "Nudge and the manipulation of choice: a framework for the responsible use of the nudge approach to behaviour change in public policy" (2013) 4 European Journal of Risk Regulation 3.

9 D Hilton, N Treich, G Lazzara and P Tendil, "Designing effective nudges that satisfy ethical constraints: the case of environmentally responsible behaviour" (2018) 17 Mind \& Society 27.

10 H Gehlbach, CD Robinson and CC Vriesema, "Leveraging cognitive consistency to nudge conservative climate change beliefs" (2019) 61 Journal of Environmental Psychology 134.

11 JI Hukkinen, "Addressing the practical and ethical issues of nudging in environmental policy" (2016) 25 Environmental Values 329.

12 Hansen and Jespersen, supra, note 8.

13 T Grüne-Yanoff and R Hertwig, "Nudge versus boost: how coherent are policy and theory?" (2016) 26 Minds \& Machines 149.

14 DM Hausman and B Welsch, "Debate: to nudge or not to nudge" (2010) 18 Journal of Political Philosophy 123. 


\section{THE NEED FOR THE ETHICS OF CLIMATE NUDGES}

Nudges raise promises in terms of guiding people towards more climate-friendly behaviour. The term "green gap" refers to the disparity between a person's positive attitudes towards climate actions and their actual behaviour. The width of this gap has been reported in several studies. ${ }^{15}$ Nilsen et al recommend nudges as an efficient tool for narrowing this gap - especially in the contexts or energy consumption and waste management. ${ }^{16}$ Sunstein suggests default nudges for decreasing emissions, such as an opt-out method for airline passenger $\mathrm{CO}_{2}$ compensation fees. ${ }^{17}$ Together with Reisch, he reports success in defaults on "print on both sides" for printers and for customer selection of green energy. ${ }^{18}$

Discussion on the philosophical ethics of climate nudges remains scarce. This may be taken to indicate that ethical discussion of climate nudges specifically is viewed as unnecessary since the general discussion on the ethics of nudging is easily applicable to them. This view can be challenged as various scholars have proposed the ethics of nudging to be somehow context specific. Holm, for example, argues against nudging in the clinical context but is ready to accept it in other areas of life:

Nudging in the clinical context raises specific issues that are distinct from the issues raised by nudging in the public health or economic context and that entail that nudging in the clinical context is almost always illegitimate. ${ }^{19}$

Holm is not alone in suggesting that nudging is not ethically problematic in general, but only in particular contexts such as organ donation ${ }^{20,21}$ or informed consent in healthcare. ${ }^{22,23}$ An extension of this acceptance of the relevance of the medical context is to ask whether the context of climate policy also raises specific ethical questions. In what follows, it is argued that climate nudges have ethically relevant features that should be acknowledged in public decision-making related to climate nudges. At least some of them may also raise further questions and require a more detailed analysis than is provided in this paper.

\footnotetext{
15 G ElHaffar, F Durif and L Budé, "Towards closing the attitude-intention-behavior gap in green consumption: a narrative review of the literature and an overview of future research directions" (2020) 275 Journal of Cleaner Production 122556

16 ASE Nielsen, H Sand, P Sørensen, M Knutsson, P Martinsson, E Persson and C Wollbrant, Nudging and Proenvironmental Behavior (Copenhagen, TemaNord 2016) p 9.

17 CR Sunstein, "Nudges, agency, and abstraction: a reply to critics" (2015) 6 Review of Philosophy and Psychology 511,515 .

18 CR Sunstein and LA Reisch, "Green by default" (2013) 66 Kyklos 398, 399.

19 S Holm, "Context matters - why nudging in the clinical context is still different" (2019) 19 American Journal of Bioethics 60, 60 .

20 T Zuradzki and K Marchewka, "Organ donor registration policies and the wrongness of forcing people to think of their own death" (2016) 16 American Journal of Bioethics 35.

21 For an opposing view, see PG Hansen, "Should we be 'nudging' for cadaveric organ donations?" (2012) 12 American Journal of Bioethics 46.

22 W Simkulet, "Informed consent and nudging" (2019) 33 Bioethics 169.

23 For an opposing view, see S Cohen, "Nudging and informed consent" (2013) 13 American Journal of Bioethics 3.
} 
Table 1. Ethical topics identified.

Ethical topics in published papers

Total

Freedom and/or autonomy

Consequentialist arguments

Concept of nudges

Personal values and preferences of nudgees

$\begin{array}{ll}\text { Responsibilities and rights of public authorities } & 31\end{array}$

Transparency

$\begin{array}{ll}\text { Inevitability of nudges } & 27\end{array}$

Comparison to other public-sector influences $\quad 25$

Democratic/public decision-making $\quad 23$

$\begin{array}{lr}\text { Nudges as a form of helping } & 20\end{array}$

$\begin{array}{lr}\text { Epistemic uncertainty } & 19\end{array}$

Human dignity 19

Comparison to private-sector influences $\quad 14$

Self-regarding versus other-regarding nudges $\quad 17$

$\begin{array}{ll}\text { Social context of nudging } & 14\end{array}$

Justice, fairness and/or equality 13

\begin{tabular}{lr} 
Consent & 12 \\
\hline
\end{tabular}

Vulnerable individuals and/or disadvantaged groups 12

$\begin{array}{lr}\text { Trust } & 10\end{array}$

$\begin{array}{lr}\text { Personal growth and/or learning } & 8\end{array}$

$\begin{array}{lr}\text { Public views } & 5\end{array}$

$\begin{array}{lr}\text { Privacy } & 4\end{array}$

$\begin{array}{ll}\text { Possibility of misuse } & 3\end{array}$

Concept of paternalism $\quad 3$

Are nudges too inefficient? 3

$\begin{array}{ll}\text { Moral responsibilities of the nudgees } & 2\end{array}$

\section{ETHICAL QUESTIONS DISCUSSED REGARDING NUDGES}

\section{Method}

In order to identify ethical questions central to climate nudges we conducted electronic searches using Philosopher's Index, Scopus and Web of Science. Surprisingly, only one relevant paper was found through the combination of the terms "nudges or nudging and climate and ethics". The combination "nudges or nudging and environment and ethics" received four hits. Since a reliance on previous scholarship on the ethical questions relevant to climate nudges thus proved unfeasible, we instead first identified the ethical questions central to all nudges in the literature and then analysed which of these questions are especially central to climate nudges.

The search on terms "nudges or nudging and ethics" provided 159 publications on Philosopher's Index. Searches on Scopus and Web of Science (with the addition of "philosophy" to the combination of terms) resulted in seven more papers. A total of twenty-seven different general ethical topics were identified from these papers (Table 1). These included, for example, the questions as to whether nudges are freedom-retaining and when nudges need to be transparent. Moreover, twenty-three 
Table 2. Contexts of nudging identified.

Contexts of nudging in published papers

Total

Healthcare (in general)

Food and eating

Organ donation

Informed consent in healthcare

Health insurance and/or retirement plans

Smoking

Accepting or refusing treatment

Clean living environment, avoiding rubbish/litter

Alcohol and other substance consumption

Traffic and transport

Environmental concerns (in general)

7

Vaccination

Drug (medicine) use

Physical exercise

Socially desirable and/or just behaviour

Climate actions

Energy consumption

Moral education

Sexual behaviour

Paying taxes

Elderly care

Gambling

Charity

different contexts of nudging, such as organ donation and traffic, were identified (Table 2). Many of the papers discussed several ethical topics and contexts. During this process, thirty papers were excluded due to their non-relevance, being written in a language other than English or non-availability, which left 129 papers for the full analysis.

\section{Results of the review}

The most discussed ethical question $(n=83)$ was whether nudging compromises the freedom or autonomy of the nudgees. The interest in this topic originates from definitions. Originally, Thaler and Sunstein define nudges as "any aspect of the choice architecture that alters people's behaviour in a predictable way without forbidding any options or significantly changing economic incentives". ${ }^{24}$ Later, this requirement has generalised into descriptions of nudges as freedom-retaining: nudges are "interventions that steer people in particular directions but that also allow them to go their own way. ... To count as such, a nudge must fully preserve freedom of choice". ${ }^{25}$

\footnotetext{
24 Thaler and Sunstein, supra, note 6, p 6.

25 Sunstein, supra, note 17, p 511.
} 
The second most common ethical topic $(n=48)$ was consequentialist argumentation, which weighs the possible and anticipated harms and benefits of nudging. Other prevalent topics were the concept of nudge $(n=40)$, non-shared preferences $(n=34)$, the rights and responsibilities of decision architects $(n=31)$, transparency $(n=28)$, the inevitability of choice architecture $(n=27)$ and comparisons between nudges and other steering methods in the public sector $(n=25)$. Some issues such as privacy and possibilities for misuse were mentioned only in very few articles.

Unsurprisingly, the most discussed context of nudging was healthcare in general $(n=44)$ followed by food and eating $(n=43)$. From the point of view of this paper, it is interesting to note the small number of articles discussing environmental or climate nudges. Eleven papers discussed clean living environments (often through mentioning the "Don't Mess with Texas" anti-littering campaign). Eight papers included discussions of traffic, seven mentioned environmental concerns in general and only three discussed climate actions and energy consumption.

\section{Identifying novel issues and disanalogies relevant to climate nudges}

Many of the above ethical issues can be resolved analogously in the climate context and in other contexts. Existing analyses on whether nudges retain autonomy, for example, are applicable to climate nudges. For some issues, however, the analogy either ceases or is weakened. In what follows, we focus on aspects of nudge ethics that merit renewed attention in the ethical analysis of climate nudges. While some of these aspects fall within the range of popular topics in philosophical nudge ethics, the existing analyses may not fully apply to climate nudges. We also highlight some aspects of nudge ethics that have not received much attention but that are, in our view, particularly important for the ethical assessment of climate nudges.

\section{Some CEntral ethical CONSIDERAtions for Climate NUdGes}

In this section, we highlight some ethical factors of climate nudges that strike us as distinct from, or not fully analogous with, nudges in other contexts. Themes that are general to all nudges fall outside the scope of this section unless the climate context places particular emphasis on them or gives rise to disanalogies in their ethical assessment.

\section{Self-regarding nudges, other-regarding nudges and climate nudges}

Nudge interventions are commonly justified by appeal to libertarian paternalism. Libertarian paternalism is "an approach that preserves freedom of choice but authorizes both private and public institutions to steer people in directions that will promote their welfare". ${ }^{26}$ Nudges are paternalistic when they constitute interference in citizens' lives in an effort to make them better off, and they are libertarian (in Thaler

26 RH Thaler and CR Sunstein, "Libertarian paternalism” (2003) 93 American Economic Review 175, 179. 
and Sunstein's sense of the word) because they are non-coercive and preserve existing options.

Most nudges aim to benefit the nudgee: these are termed self-regarding nudges in M'hamdi et al. ${ }^{27}$ Typical examples are nudges related to health behaviours. Yet nudging methods can also be used to create what M'hamdi et al term "otherregarding nudges". Examples include nudges for organ donation ${ }^{28,29}$ and tax paying. ${ }^{30}$ The primary beneficiary of an other-regarding nudge is someone other than the nudgee. Both self-regarding and other-regarding nudges may also have secondary effects. Other-regarding nudges may result in secondary benefits that fall on the nudgee: for example, nudges towards charitable giving may also result in improved mood. Likewise, self-regarding nudges may have secondary other-regarding benefits.

Climate nudges are not self-regarding in the sense that they would primarily benefit the nudgee. Thus, at first sight, they appear other-regarding. Yet the benefits form the climate nudges fall on numerous people - including the nudgee and members of future generations. Moreover, since climate change is connected to environmental harm, the beneficiaries conceivably also include animals, plants, species and ecosystems. Thus, in the case of climate nudges, the term "other-regarding nudge" should either be understood very broadly or replaced with a new term such as "allregarding nudge". The term "all-regarding nudge" may, however, be inaccurate in cases where the costs of climate nudging for the nudgee are greater than gains they get from it.

The question of beneficiaries relates intimately to the ethics of nudging. The justifications for self-regarding nudges are typically paternalistic. The justifications for other-regarding nudges cannot be paternalistic, at least if paternalism is understood as state interference justified by benefits to the person being interfered with. ${ }^{31,32}$ Even if climate nudges are understood as all-regarding, the paternalistic justification is insufficient. Rather, the justification must follow from the benefits to other people, future generations and other living beings, or from other nonpaternalistic grounds. Hilton et al argue that "a law, tax or nudge that protects the public by discouraging individuals from anti-social behaviour does not need to be justified on paternalistic grounds. Instead they address a market failure". ${ }^{33}$ For Hilton et al, environmental nudges fit that bill. Likewise, Sunstein and Reisch suggest that the justification of climate nudges could lie in externalities, in light of which nudges aimed at reducing emissions could be justified on cost-benefit grounds. ${ }^{34}$

In summary, the justification of climate nudges does not flow easily from a standard paternalistic standpoint. Rather, either flexibility needs to be introduced into the

27 HI M'hamdi, M Hilhorst, EAP Steegers and I de Beaufort, "Nudge me, help my baby: on other-regarding nudges" (2017) 43 Journal of Medical Ethics 702.

28 A Sharif and G Moorlock, "Influencing relatives to respect donor autonomy: should we nudge families to consent to organ donation?" (2018) 32 Bioethics 155.

29 Engelen, supra, note 4.

30 Sunstein, supra, note $17, \mathrm{p} 514$.

31 G Dworkin, "Paternalism" in EN Zalta (ed.), The Stanford Encyclopedia of Philosophy (Fall 2020 edition) $<$ https://plato.stanford.edu/archives/fall2020/entries/paternalism/> (last accessed 24 July 2021).

32 Hobbs, supra, note 5, p 39.

33 Hilton et al, supra, note 9, p 29.

34 Sunstein and Reisch, supra, note 18, p 401. 
conception of paternalism or climate nudges need to operate on a justification that is categorically different from the libertarian paternalist justification of most nudges. Examples of possible justifications that do not follow from libertarian paternalism include, for example, utilitarian justifications and ones based on the rights of future generations.

\section{Climate change denialists}

Some climate change denialists deny the scientific consensus regarding anthropogenic climate change. Others admit that global warming is taking place but oppose taking action towards mitigating to it. These people should be accounted for in welldesigned climate nudging. Here, two concerns are relevant: that of nudging against the will and values of some citizens and that of effectiveness.

Many hold that nudges should accord with the preferences of the nudgees - including their normative standards. ${ }^{35,36,37,37}$ A citizen may object to being nudged either because they do not want or value the objective of the nudge, such as in the case of climate change denialists, or because while they want or value the objective of the nudge, they do not wish to be nudged to behave accordingly. ${ }^{38}$ This latter, autonomy-based concern is general to all nudges (and to almost any steering policy).

While many hold that nudges should accord with the values of nudgees, given epistemic constraints on finding out the values of specific individuals, in practice nudges operate on the level of a group of nudgees. For practical policymaking, the relevant consideration therefore is that nudges should accord with the values that are sufficiently prevalent within the population being nudged. The implication is that the minority can make use of the other feature of nudges, namely that they are option-preserving. Thus, at first sight, climate nudges do not differ from other nudges in this respect (as long as the target population can reasonably be expected to consist mainly of non-denialists). While climate change denialists may object to climate nudges, this is not unlike, say, the dedicated carnivore's opposition to nudges towards vegetarian options. Recalling that nudges are not compelling, a climate nudge is a nudge only if it allows for the denialist to keep acting according to their ideology. This requirement of retaining the options is common to all nudges regardless of whether they target health, wealth, climate or other features. However, acting according to one's ideology is possible only if one can distinguish which alternatives accord with it; this challenge will be discussed in the next section.

As for effectiveness, the impact of climate change denialism is twofold. First, denialism impacts the behaviour of the denialist. Second, it impacts the scope of policies that are feasible. For the first sort of impact, climate change denialism does not have a substantive effect on the carbon footprint of the individual: rather than political or climate beliefs, the primary correlate of the carbon footprint is socioeconomic

\footnotetext{
W Glod, "How nudges often fail to treat people according to their own preferences" (2015) 41 Social Theory and Practice 599.

36 D Scoccia, "Paternalisms and nudges" (2019) 35 Economics and Philosophy 79.

$37{ }^{37}$ S Conly, Against Autonomy: Justifying Coercive Paternalism (Cambridge, Cambridge University Press 2013).

37 Engelen, supra, note 4, p 50.

38 See Glod, supra, note 35, p 604.
} 
status. ${ }^{39}$ In other words, attitudes towards climate actions have little direct effect on the carbon footprint. Instead, the impact of denialism on behaviour is aversion towards climate matters, and thus stating the intended climate benefit of the nudge may decrease its effectiveness in steering denialist behaviour. This pragmatic consideration is in tension with the requirement that it should be possible for nudgees to select among possible options based on their values. This kind of tension concerns all nudges but is especially pressing regarding climate nudges as they lack paternalistic justification.

Climate change denialists are a marginal but vocal group whose presence in public discussions may hinder the public acceptance of various forms of climate policy, not just climate nudges. For this reason, some believe denialists ought to be nudged to accept the reality of global warming and the desirability of climate-friendly behaviour. ${ }^{40}$ However, climate nudges targeting denialists specifically do not conform to the desideratum that nudges should be aligned with the values of the nudgees. Yet when the aim is to alter beliefs rather than behaviours specifically, this desideratum may in some cases cease to be consistent. Levy suggests "nudging to reason" as an acceptable class of nudges that would, if successful, make persons more sensitive to genuine evidence. ${ }^{41}$

Whether or not nudges to reason are a feasible possibility, a further workaround remains: to avoid nudging denialists altogether and relying instead on changing the status quo with the help of more willing participants. Computational models yield some indication that a $25 \%$ minority norm has the potential to become the new predominant norm of behaviour. ${ }^{42}$ If further studies confirm this, the collaboration of denialists may not be necessary for creating climate-friendlier societal norms of behaviour. When new societal norms are established, denialists will, in time, follow suit in terms of behaviour.

\section{Transparency}

The transparency of nudges refers to so-called type interference transparency and token interference transparency. Type interference transparency means that a government informs citizens that it uses nudge methods but does not necessarily make it possible for citizens to notice each nudge. Token interference transparency means that a particular intervention can be easily identified as a nudge. ${ }^{43}$ Type interference transparency is quite generally accepted as a necessary condition for ethically acceptable nudging. ${ }^{44,45}$ This implies that other requirements - including token

\footnotetext{
39 S Moser and S Kleinhückelkotten, "Good intents, but low impacts: diverging importance of motivational and socioeconomic determinants explaining pro-environmental behavior, energy use, and carbon footprint" (2018) 50 Environment and Behavior 626.

40 D Lenzi, "Deliberating about climate change: the case for "thinking and nudging"” (2019) 6 Moral Philosophy and Politics 313.

41 N Levy, "Nudges in a post-truth world" (2017) 43 Journal of Medical Ethics 495.

42 D Centola, J Becker, D Brackbill and A Baronchelli, "Experimental evidence for tipping points in social convention" (2018) 360 Science 1116.

43 L Bovens, "Ethics of nudge", in T Grüne-Yanoff and SO Hansson (eds), Preference Change: Approaches from Philosophy, Economics and Psychology (Berlin, Springer 2008) p 216.

44 AT Schmidt, "The power to nudge" (2017) 111 American Political Science Review 404.

45 Hansen and Jespersen, supra, note 8, p 17.
} 
interference transparency - may not need to be fulfilled in some instances of nudging, but nudging cannot be ethical if it is not type interference transparent. This raises interesting questions. Does the government need to inform citizens about the contexts, aims or methods of nudging used? Or is it sufficient just to notify that it uses nudges without specifying where, when and why nudges are used? These questions are analogous with respect to climate nudges and other nudges.

Nudges are token interference transparent to different degrees. Verbal framing is often quite opaque, while gamifying the environment is usually easy to notice. ${ }^{46}$ The degree of transparency does not depend merely on the method chosen, but also on the nudgees and their situation. An educated individual in a familiar environment and peaceful situation is more prone to realise that they are being nudged than a less educated person who is under stress in a foreign milieu. ${ }^{47}$ The degree of transparency of food arrangement nudges, for example, depends on several factors, such as the information provided to the nudgees, the methods of arrangement as well as the earlier experiences, current situation and knowledge level of the customers. ${ }^{48,49}$

Whether, on what condition and to which extent nudges should be token interference transparent has been discussed to some extent. Transparency enhances the feasibility of selecting alternative options in case a nudge is against nudgees' normative commitments. However, it may also diminish the effectiveness of the nudge and thus diminish the expected benefits. ${ }^{50,51,52}$ (Interestingly, transparency can also make some nudges more efficient. ${ }^{53,54}$ ) The strictest ethical requirement regarding token transparency would require that each nudgee is aware of being nudged at each occasion of nudging. In practice, this would imply that every nudge must be accompanied by a clearly visible notification that it is taking place. This kind of requirement is generally agreed to be over-demanding as it would imply, for example, that gamified rubbish bins (meant to promote recycling) or reorganised parking arrangements (which encourage the use of environmentally friendly transportation) would only be acceptable if each nudgee were to receive information about them. Rather, ethical nudging usually is seen to require in principle token interference transparency or reasonable token interference transparency, meaning that a watchful individual could, without unreasonable effort, notice that it is taking place. ${ }^{55,56,57}$

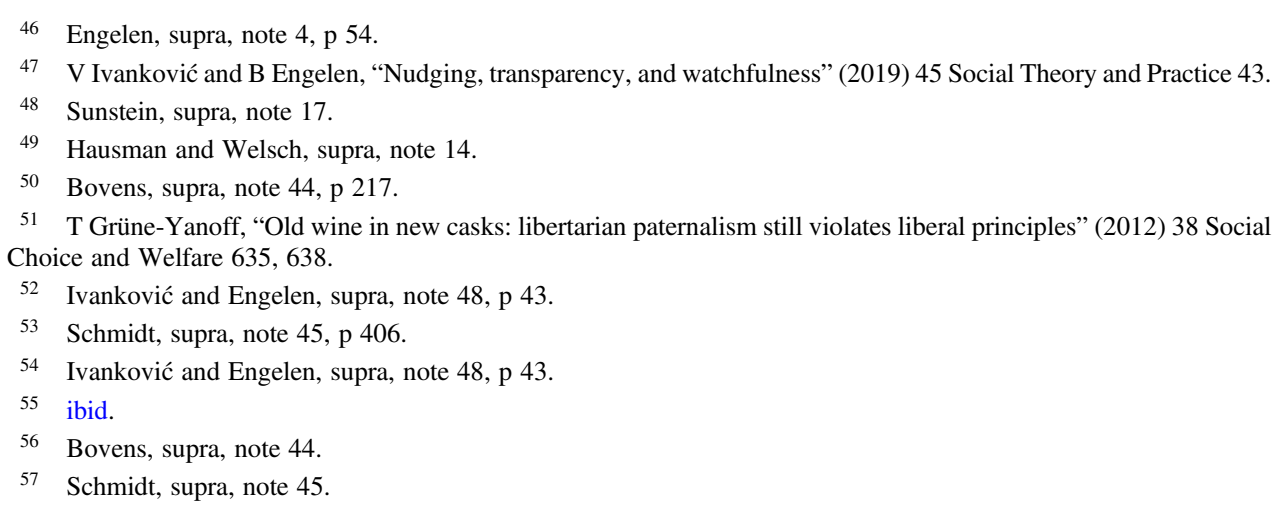


Transparency also raises special considerations regarding climate nudges. These considerations relate to the distinction between transparency about means and transparency about ends. ${ }^{58}$ Hansen and Jespersen tie these two together:

A transparent nudge is defined as a nudge provided in such a way that the intention behind it, as well as the means by which behavioral change is pursued, could reasonably be expected to be transparent to the agent being nudged as a result of the intervention. ${ }^{59}$

Hansen and Jespersen take a nudge to be transparent when a watchful individual could, without unreasonable effort, realise that they are being nudged to behave in the way $W$ for the reason $R$. A climate nudge is transparent in this sense, for example, when a nudgee can easily notice that they are nudged towards cycling (instead of driving) in order enhance the state of the climate. However, for many climate nudges, transparency regarding means does not imply transparency regarding intentions. ${ }^{60}$ A nudgee may well realise that they are being nudged towards cycling without gaining any information on why someone wants them to increase their cycling behaviour. Furthermore, nudgees can misinterpret the intentions behind nudging. Many climate nudges (eg nudges for cycling or for reducing meat consumption) can easily be construed as health nudges. When climate nudges encourage saving energy or other resources, they may be misunderstood as nudges for financial prudence.

The possibility of misunderstandings is intimately connected to climate change denialism. It was stated in the previous section that a climate nudge is a nudge only if it allows the denialist to keep acting according to their ideology. The question is: what degree of transparency regarding intentions suffices to preserve this sort of freedom in climate nudging? For example, a citizen who might condone being nudged to cycle for health purposes may strongly oppose being nudged to cycle for climate reasons. In short, people may oppose being nudged to behave in a certain way not only because of the overt behaviour itself, but also for the reasons why they are being nudged towards that behaviour. ${ }^{61}$ However, when balanced with other considerations, including the seriousness of the climate crisis (to be discussed in the final section of this paper), it is not self-evident that intention-transparent climate nudges are necessarily ethically superior to intention-opaque climate nudges. Rather, the ethical acceptability and desirability of a climate nudge should be weighted from the points of view of several factors addressed in this paper.

\section{Knowing the right or best behaviours}

All nudges presuppose judging some alternatives better than others. The classic "cafeteria nudge", for example, rests on the assumption that the manager can easily distinguish

\footnotetext{
Ivanković and Engelen, supra, note 48, p 53.

Hansen and Jespersen, supra, note 8, p 17.

60 Ivanković and Engelen, supra, note 48, p 53.

61 Ivanković and Engelen, supra, note 48.
} 
between healthy and non-healthy alternatives. As Lenzi points out, the presence of choice architects who competently assess what sorts of behaviours to promote is often taken for granted. ${ }^{62}$ However, rather than being specific to nudging, this presumption is general to public policy where the assumption is that policymakers are (sufficiently) well placed to make beneficent decisions. In democracies, policymakers are expected to justify their choices concerning what sorts of behaviours are promoted. As discussed above, with respect to nudges this justification is often verbalised as the requirement of type interference transparency. ${ }^{63,64}$

However, for climate nudges as well as for any public climate policy aiming to steer the general population, assessing which particular behaviours should be nudged towards can sometimes be a challenge. Even though there is consensus on appropriate actions regarding climate change in the broad sense (eg cutting greenhouse gas emissions) and even though there is consensus that some habits are especially harmful to the environment (eg flying and meat consumption), ideological reasons as well as the complexity of the causal networks underlying climate change generate disagreement concerning which changes to citizen behaviour are the most effective ones.

The challenges in identifying the most efficient and feasible climate actions are increasingly ones that require complex and multifactorial cost-benefit and feasibility assessments. Policymakers may, in the climate context specifically, be better placed to choose the best behaviours than citizens are. As a result, nudging towards particular climate-friendly actions rather than steering generally towards climatefriendliness may be preferable because citizens, attempting to decrease their impact on the climate, may replace their existing behaviours with options that are in fact less climate-friendly. For this reason, "boosts" or "nudges to reason" may not be the most efficient choices in the context of climate nudges. ${ }^{65,66}$

However, even if policymakers are better placed to assess the actual climate impact of various actions, this is not always a simple feat. For newer innovations particularly, the long-term emissions from their production, care and how often they are replaced may be subject to uncertainty. If there are more uncertainties regarding climate actions than there are regarding, for example, health actions, then climate nudging includes more uncertainties than health nudging, which places higher demands on the expertise of choice architects for climate nudges. Climate nudging thus requires particular diligence in nudging only towards behaviours that in fact are beneficial to the climate.

\section{Justice}

Ethical considerations surrounding climate nudges include both local and global justice. The global justice questions arise from the fact that mitigating climate change implies costs and burdens for societies and nation-states. How should these be divided?

\footnotetext{
62 Lenzi, supra, note 41, p 325.

63 Hansen and Jespersen, supra, note 8.

64 Schmidt, supra, note 45.

65 R Hertwig and T Grüne-Yanoff, "Nudging or boosting: steering or empowering good decisions" (2017) 12 Perspectives on Psychological Science 973.

66 Levy, supra, note 42.
} 
Several principles such as "The Polluter Pays", "The Beneficiary Pays" and "The Ability to Pay" have been suggested for global climate policy, but the questions about duties and responsibilities remains open. ${ }^{67}$ When applied to nudging, the big question is which governments have the strongest duty to significantly invest in nudging programmes and to start to nudge their citizens towards more climate-friendly actions. The most plausible answers likely accord with general global climate justice theories. No feature of nudging implies that the burden of governments regarding it should be distributed differently from the burdens entailed by other climate policies. However, given that nudging methods are "soft", additional questions arise: which (if any) societies are entitled to prioritise nudging or to settle for it instead of stronger and more efficient methods such as direct bans and restrictions? How should climate nudging and more efficient (but also politically less appealing) methods be balanced? For further discussion on whether nudges are sufficiently efficient, see the next section.

Questions of local justice concern the distribution of the costs and benefits of nudging between individuals within the target population being nudged. While nudges should not include significant economic incentives, there are many possible costs to climate nudges. A nudge towards winter cycling in cold climates, for example, implies costs for the nudgees who choose to comply with it. These may include the monetary cost of winter tyres and appropriate clothing and the additional time used for transport (if cycling implies giving up a faster means of transport), as well as possible accident and health risks related to icy winter conditions. On the other hand, nudgees may also benefit from climate nudging. In the case of winter cycling, the possible benefits include secondary benefits such improved health resulting from the exercise and enjoyment of riding a bicycle (one of the authors is among those who find cycling in icy conditions enjoyable; the other author has the opposite disposition). Moreover, intention-transparent nudges may diminish climate anxiety and bring about psychosocial benefits related to experiences of togetherness, altruism and solidarity. The questions about justice concern the distribution of these possible costs and the benefits of making choices within a given target population, whether their choices accord with the aims of the nudge or not.

Fowler and Roberts criticise nudging programmes for all too often assuming that nudgees are a homogeneous group with equal access to the necessary resources to be effectively nudged. According to them:

[N]ot all choices are equally available to everyone ... [In cafeteria nudges, the] clever placement of fruit and vegetables will not convince someone who simply cannot afford [them] ... The very nature of choice architecture as a policy intervention assumes that people have access to meaningful choices. ${ }^{68,69}$

\footnotetext{
67 S Caney, "Climate justice" in EN Zalta (ed.), The Stanford Encyclopedia of Philosophy (Summer 2020 edition) $<$ https://plato.stanford.edu/archives/sum2020/entries/justice-climate/> (last accessed 28 July 2021).

68 LR Fowler and JL Roberts, “A nudge toward meaningful choice” (2019) 19 American Journal of Bioethics 76, 76.

69 For similar views, see also J-F Ménard, "A 'nudge' for public health ethics: libertarian paternalism as a framework for ethical analysis of public health interventions?” (2010) 3 Public Health Ethics 229.
} 
Roberts argues that vulnerable populations and particularly the most disadvantaged individuals are "nudge-proof" in certain contexts. No matter how well-designed the nudges are, some individuals cannot enact the behaviours that the nudges are designed to promote. For example, a nudge for physical exercise is hopelessly inefficient when the nudgee lacks time, social support (eg a babysitter) and/or access to a safe exercising environment. ${ }^{70}$ Returning to the climate nudge for winter cycling, it seems unlikely that safe and comfortable winter cycling would be accessible to all members of a given society. Thus, nudges may leave behind those in greatest need and in the most vulnerable positions. ${ }^{71}$ This threat is most pressing regarding health nudges and other self-regarding nudges. Yet this concern should also be acknowledged in climate nudge design and development - especially when the nudges used rely on enhancing social status, diminishing climate anxiety or building positive experiences, such as a sense of togetherness, for the nudgees. ${ }^{72}$ On the other side of the coin, some nudges (eg default options) work especially well on less welloff individuals. ${ }^{73,74}$

As noted above, the nudgees' ability to notice nudges is situation sensitive. ${ }^{75}$ Thus, nudges that are in principle token inference transparent may in practice be most opaque to individuals who are - because of their history or current life situation - in a vulnerable position. Since individuals are more prone to resist those nudges that they notice, less well-off individuals may be more likely to enact the desired behaviour. As a result, when choosing according to the aims of a nudge implies costs (eg loss of time or loss of a pleasure), those costs may turn out to be paid by those members of society who in the beginning had less. This possibility calls for extra attention when designing other-regarding or all-regarding nudges such as climate nudges. Moreover, as Roberts points out, nudges that imply only minimal costs to the average citizen may be harmful for some of the more vulnerable citizens. As an example, she discusses opt-out system for green energy. Less well-off individuals are more likely to stay on the default. At the same time, they are the ones who suffer most from buying the more expensive green energy. This example illustrates that there sometimes are ethical rationales for using economic incentives (eg lowering the price of the green energy) in conjunction with nudging. ${ }^{76}$

The justice concerns do not, as such, imply that climate nudges would be ethically unacceptable or problematic. However, they are a factor that should be acknowledged in nudge design and implementation and weighed together with other relevant factors presented in this paper. Even though other morally relevant issues may sometimes outweigh the unfairness of a particular nudge, it is also easy to accept that prima facie just nudges should be preferred to ones that aggravate inequalities. Well-designed

70 Roberts, supra, note 7, p 1048.

71 Fowler and Roberts, supra, note 69.

72 Hobbs, supra, note 5 .

73 CR Sunstein, Why Nudge? Politics of Libertarian Paternalism (New Haven, CT, Yale University Press 2014) p 179.

74 Roberts, supra, note 7, p 1056.

75 Ivanković and Engelen, supra, note 48, p 53.

76 Roberts, supra, note 7, p 1056. 
nudges can also promote justice. Consequently, the allocation of the costs and benefits of climate nudges should be a concern to policymakers and an integral part of good nudge design.

\section{Weighing the effectiveness of nudging against the seriousness of the climate crisis}

Finally, a central question regarding climate nudges is whether their effectiveness is sufficient to justify them in a context as serious as the climate crisis is. Effectiveness here refers to the changes in actual behaviour brought about by the nudge. The challenge is that some nudges may score low in their effectiveness even though they show high efficacy in controlled (laboratory) conditions. ${ }^{77}$ Mitigation of climate change requires lasting changes in behaviour. The empirical question is whether nudges are suitable for bringing about the required changes or whether some other feasible methods are more effective - either as such or in relation to their costs.

Being relatively cheap to implement, nudges tend to score well in cost-benefit analyses. The most efficient nudges, however, are based on the use of defaults (optout instead of opt-in) regarding decisions that are done only once or rarely. ${ }^{78}$ Default nudges are less readily applicable to the climate context. ${ }^{79}$ The behavioural changes required to mitigate climate change are long-lasting; however, the jury is still out regarding the persistence of nudge effects after the nudge intervention is no longer present. While nudging can yield short-term results, there is a risk of backsliding. ${ }^{80}$ The backsliding phenomenon refers to the behavioural impact of a policy "wearing off" after a period of time. The body of longitudinal data on nudging continues to be slim. Allcott and Rogers show that nudge effects decreased over time but did not disappear entirely, whereas Ferraro et al demonstrate that a social comparison-based setup produced effects that could still be detected two years after the intervention. ${ }^{81,82}$ Due to the small volume of longitudinal data, we should be cautious about the generalisability of these promising data. Low confidence regarding the long-term effects of nudging will continue to be justified until a larger body of research is available.

While the worry about sustained effects is general to many nudges, it is particularly pressing for climate nudges given the gravity of the climate crisis: for some health nudges, for example, we can consider short-term improvement a success, but given the time sensitivity and catastrophic impacts of climate change, short-term improvements may amount to futile exercises in the sphere of climate policy. At their

\footnotetext{
77 For further discussion, see E Ernst and MH Pittler, "Efficacy or effectiveness?" (2006) 260 Journal of Internal Medicine 488.

78 For organ donation, see MU Ahmad, A Hanna, A-Z Mohamed, A Schlindwein, C Pley, I Bahner, R Mhaskar, GJ Pettigrew and T Jarmi, "A systematic review of opt-out versus opt-in consent on deceased organ donation and transplantation (2006-2016)" (2019) 43 World Journal of Surgery 3161.

79 JM Jachimowich, S Duncan, EU Weber and EJ Johnson, "When and why defaults influence decisions: a metaanalysis of default effects" (2019) 3 Behavioural Public Policy 159.

80 H Allcott and T Rogers, "The short-run and long-run effects of behavioral interventions: experimental evidence from energy conservation” (2014) 104 American Economic Review 3003.

81 ibid.

82 PJ Ferraro, JJ Miranda and MK Price, "The persistence of treatment effects with norm-based policy instruments: evidence from a randomized environmental policy experiment” (2011) 101 American Economic Review 318.
} 
worst, climate nudges and other minor improvements may postpone of hinder the implementation of major, necessary changes as the minor improvements give people the impression that they are already doing their share (or at least something).

Another effectiveness limitation of nudges is that they are behaviour specific (ie they target a particular behaviour, such as mode of commuting or energy use, rather than generating general changes towards sustainability across citizens' behaviours). This makes behavioural public policy vulnerable to the worries outlined in the previous sections.

A further worry is that even if nudges were effective, they would be pedagogically counterproductive. Bovens worries that nudges may be self-defeating in the long term, as "[r]egulation as well as environmental cues to discourage or encourage certain behaviour may leave the agent with a lack of moral strength to implement the target behaviour once the regulation or the environmental cues are no longer present". ${ }^{83}$ Furedi goes even further in stating that nudge policies may erode citizens' capacity to exercise judgment. ${ }^{84}$ Bovens and Furedi seem to believe that public policy should not just steer towards the practical upshots of citizens' choices, but rather good policymaking involves moral pedagogy, and that nudging may fail to cultivate citizens' moral agency. ${ }^{85}$ However, as discussed above, some forms of nudging can even enhance individuals' morality and rationality. ${ }^{86,87}$ Yet the issue remains speculative, as there are no longitudinal studies concerning the impact of nudges on moral agency.

Additionally, it can be questioned whether any policy targeting citizen behaviour, including nudging, is the correct response to the climate crisis. This is because nearly two-thirds of global carbon emissions can be traced back to ninety industrial corporations. $^{88}$ Are citizens the entities that need to change their behaviour to mitigate climate change, or should regulation that targets the private sector instead be prioritised? Whether opponents of stricter regulation of the private sector are correct in arguing that this would have adverse effects on the economy, it may be that in the face of corporate lobbying and other effects on public policy that slow down regulation of the private sector, nudging citizens remains a viable climate policy not because it is the best imaginable policy but because it can be done.

Given the gravity of the climate crisis, it may be objected that nudges are unacceptable simply because they are a soft form of policy: serious matters that are a threat to the ecosystem and to human life should call for stricter policy. Here, of course, nudging can also be used to supplement strict policy: no climate policy should consist solely in nudging but, instead, a combination of soft and hard policy should be used, and

\footnotetext{
83 L Bovens, "Real nudge" (2012) 1 European Journal of Risk Regulation 43, 44.

84 F Furedi, "Defending moral autonomy against the army of nudgers" (Spiked, 2011) <https://www.spiked-online. com/2011/01/20/defending-moral-autonomy-against-an-army-of-nudgers/> (last accessed 20 August 2021).

85 For further discussion, see Hobbs, supra, note 5.

86 AT Schmidt and B Engelen, "The ethics of nudging: an overview" (2019) 15 Philosophy Compass 4, 5.

87 Levy, supra, note 42.

88 B Ekwurzel, J Boneham, MW Dalton, R Heede, RJ Mera, MR Allen and PC Frumhoff, "The rise in global atmospheric $\mathrm{CO}_{2}$, surface temperature, and sea level from emissions traced to major carbon producers" (2017) 144 Climatic Change 579.
} 
soft policy can also be used to ensure compliance with regulations. The ethical question for any climate action designer is the weighting of different methods. If nudges alone are not sufficient, do they add value to other methods? If yes, how should the different methods be weighted in policy solutions and in the prioritisation of policymakers' resources?

\section{Conclusion}

The aim of this paper has been to discuss disanalogies between climate nudges and nudges in other contexts, as well as to provide an overview of some central ethical considerations in the development of climate nudges. We have spelled out six morally relevant features of climate nudges - that is, features that need to be taken into account in designing them. These include the justification of nudges that are not self-regarding; accounting for climate change denialists; transparency; knowing the right or best behaviours; justice concerns; and whether nudges are sufficiently efficient and reliable to be justified as a form of climate policy.

We argue that the ethical assessment of climate nudges needs to be pluralistic in the sense of taking into account all of these six factors, as well as factors that concern all nudges (eg questions regarding freedom). All of these factors are prima facie in character. The prima facie character of an ethical factor means that a climate nudge should accord with it unless another - on that occasion stronger and more important factor trumps it. ${ }^{89,90}$ Ethical considerations, including the ones discussed in this paper, in practice often are in friction with each other. For instance, improving the transparency of a climate nudge may decrease its effectiveness. Likewise, duly accounting for climate denialists may sometimes stand in friction with global justice considerations. As a result, the ethical assessment of nudges involves weighing the ethically relevant factors against each other.

The presented type of understanding of ethical assessment and decision-making seldom (if ever) rests on a static view regarding the strength and importance of different ethically relevant factors. Rather, the prioritisation of different ethical considerations is situation sensitive. ${ }^{91}$ As a result, the ethical assessment of climate nudges includes three stages: (1) spelling out any morally relevant considerations (including the ones listed in this paper); (2) analysing whether the proposed nudge accords with these factors; and (3) justification of any deviation from these factors. In this final stage, any conflicts between the ethical factors are analysed, and the prioritisation of some considerations over others is justified by referring to which ethical factors are the most important in that particular situation. Since the practical conflicts between the relevant factors are common, the central outcome of the ethical

\footnotetext{
89 M DePaul and A Hicks, "A priorism in moral epistemology" in EN Zalta (ed.), The Stanford Encyclopedia of Philosophy (Summer 2021 Edition) <https://plato.stanford.edu/archives/sum2021/entries/moral-epistemology-apriori/> (last accessed 20 August 2021).

90 JF Childress, "A principle-based approach" in H Kuhse and P Singer (eds), Companion to Bioethics (Hoboken, NJ, Blackwell Publishers 2001).

91 ibid.
} 
assessment of climate nudges typically involves the situation-specific justification of prioritising some ethical considerations over others.

In this paper, our aim has not been to argue that climate nudges are morally more problematic than other nudges. On the contrary, we believe that climate nudges may provide an effective and interesting tool for enhancing climate-friendly behaviour. However, acknowledging the ethical questions that climate nudges raise should be included in their design. 